\section{Treatment of Highly Aberrated Eyes Using the NIDEK CXIII Excimer Laser}

\author{
Damien Gatinel, MD, PhD; Harkaran S. Bains
}

\section{ABSTRACT}

PURPOSE: To describe the treatment of highly aberrated eyes due to previous excimer laser surgery or trauma.

METHODS: Three eyes (three patients) with reduced visual quality due to previous decentration or corneal laceration (one eye) underwent topography-guided ablation using the CXIII excimer laser (NIDEK Co Ltd) to correct residual refractive error and/or wavefront aberrations.

RESULTS: Postoperatively, one patient had a one-line increase in corrected distance visual acuity (CDVA) with a reduction in visual symptoms. At 2 months postoperatively, one patient maintained CDVA, increased uncorrected distance visual acuity from 20/20 to $20 / 15$, and reported resolution of monocular diplopia. In all cases, the functional optical zone increased and wavefront aberrations decreased with selective flattening of the intended corneal region.

CONCLUSIONS: Topography-guided ablation is an effective treatment of severe corneal aberrations due to surgery or trauma and can be selectively used to treat higher order aberrations with or without refractive error. [J Refract Surg. 2010;26(6):453-457.] doi:10.3928/1081597X-20100212-05

$\mathrm{T}$ he induction of higher order aberrations (HOA) due to surgery or corneal trauma may cause a reduction in visual quality. ${ }^{1,2}$ Topographyguided treatment appears to be a predictable modality to address such cases. ${ }^{3,4}$ Wavefront-guided treatments may not be appropriate for highly aberrated eyes due to measurement artifacts of Hartmann-Shack aberrometers such as crossover of centroids and data smoothing of clinically significant irregularities. ${ }^{5,6}$

Severely aberrated eyes due to corneal leukoma and central islands have been treated with corneal topography-guided aspheric algorithms. ${ }^{3,4}$ In the current study, we describe the use of the Custom Aspheric

From Rothschild Foundation (Gatinel, Bains); AP-HP Bichat Claude Bernard Hospital, Paris VII University (Gatinel); and Center of Expertise and Research in Clinical Optics (Gatinel), Paris, France.

Dr Gatinel has no proprietary interest in the materials presented herein. Mr Bains is a clinical consultant for NIDEK Co Ltd, Gamagori, Japan.

Correspondence: Damien Gatinel, MD, PhD, Rothschild Foundation, 25 rue Manin, 75019 Paris, France. Tel: 3314803 64 82; Fax: 331480364 87; E-mail: gatinel@aol.com

Received: November 24, 2008; Accepted: January 13, 2010

Posted online: February 15, 2010
Treatment zone algorithm (CATz) (NIDEK Co Ltd, Gamagori, Japan) with the NIDEK Advanced Vision Excimer Laser Platform (NAVEX) to treat eyes with reduced visual quality due to decentered ablations and corneal laceration.

\section{CASE REPORTS}

In all cases, Final Fit software version $1.11 \mathrm{~T}^{3,4}$ (NIDEK Co Ltd) was used to plan treatments based on corneal topography data acquired with the OPD Scan II (NIDEK Co Ltd). The CATz algorithm delivers aspheric treatment zones combined with the treatment of corneal elevation irregularities or corneal wavefront (at the surgeon's discretion). The CATz ablation algorithm uses a combination of optical and transition zones that gradually taper the corneal curvature paracentrally and peripherally, blending together to create a single treatment zone or ablation zone. The Final Fit software allows selection of eight ablation profiles that gradually increase in asphericity as the profile number increases. A number of treatment parameters can be manipulated during surgical planning, including laser treatment zones, ablation profile, volume of corneal irregularity to be removed, and reduction of corneal irregularity with or without treatment of refractive error.

\section{RetreatMent OF DECEnTRATIONS}

Case 1. A 35-year-old woman was referred after inferior decentration from previous "wavefront optimized" LASIK in the left eye. Uncorrected and corrected distance visual acuities (UDVA and CDVA, respectively) were 20/20 with patient complaints of monocular vertical diplopia and glare. Manifest refraction spherical equivalent (MRSE) was plano. Slit-lamp examination was unremarkable. An inferonasal decentration (Fig 1) caused a 7.00-diopter (D) refractive gradient across the pupil. Higher order aberration root-mean-square (RMS) was $1.16 \mu \mathrm{m}$ with coma $(0.531 \mu \mathrm{m})$ dominating the wavefront profile. Examination of the higher order point spread function (PSF) indicated a comet-shaped image, indicating coma was decreasing objective visual quality. We elected to treat the "irregularity" component only using the "corneal wavefront" option in Final Fit software without refractive correction as the source of visual degradation was corneal. The corneal flap was relifted and ablation was performed using a 6.5-mm optical zone and 7.5-mm transition zone, removing $15.90 \mu \mathrm{m}$ of stromal tissue. Large treatment zones were used to maintain large functional optical zones postoperatively. Five months after CATz treatment, the refractive gradient was reduced to $2.00 \mathrm{D}$ (see Fig 1, case 1). Postoperatively, there was superotemporal flattening (see Fig 1, case 1) and HOAs 


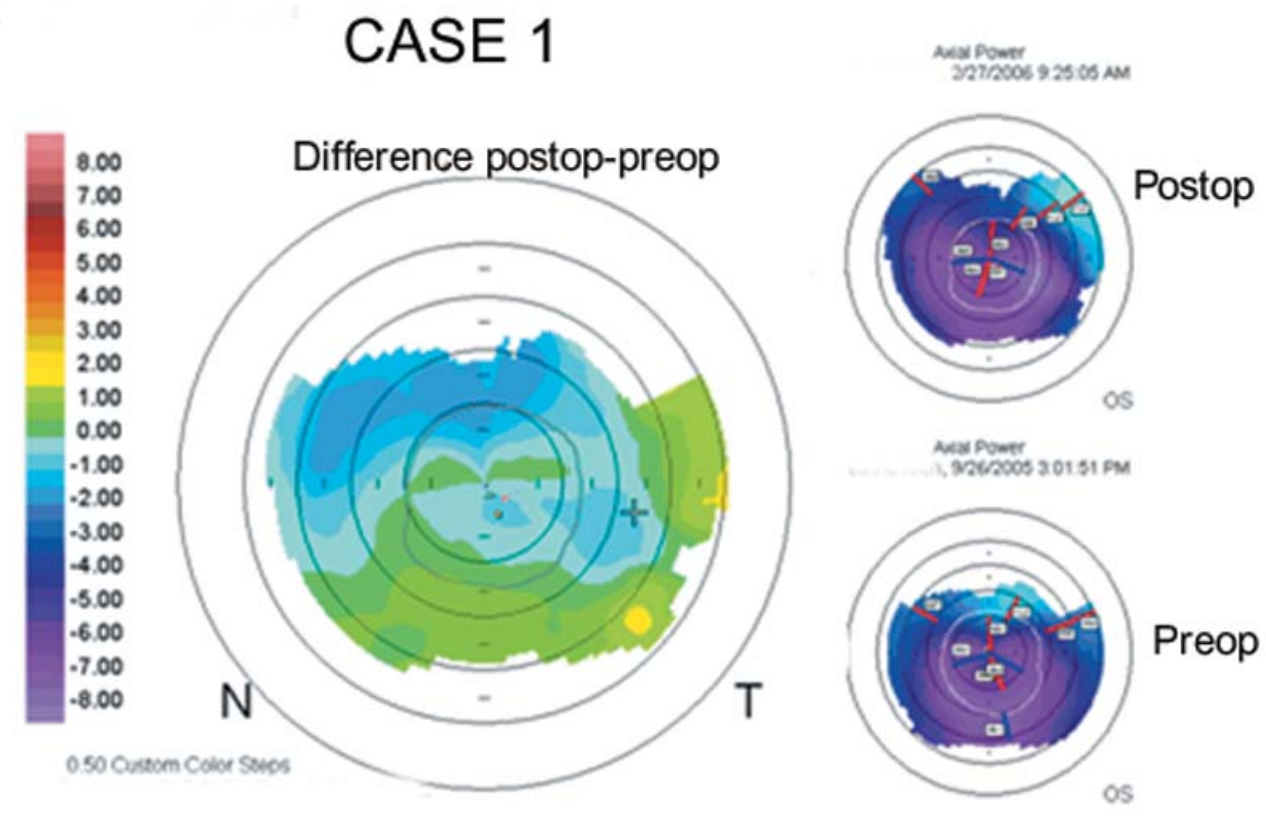

CASE 2
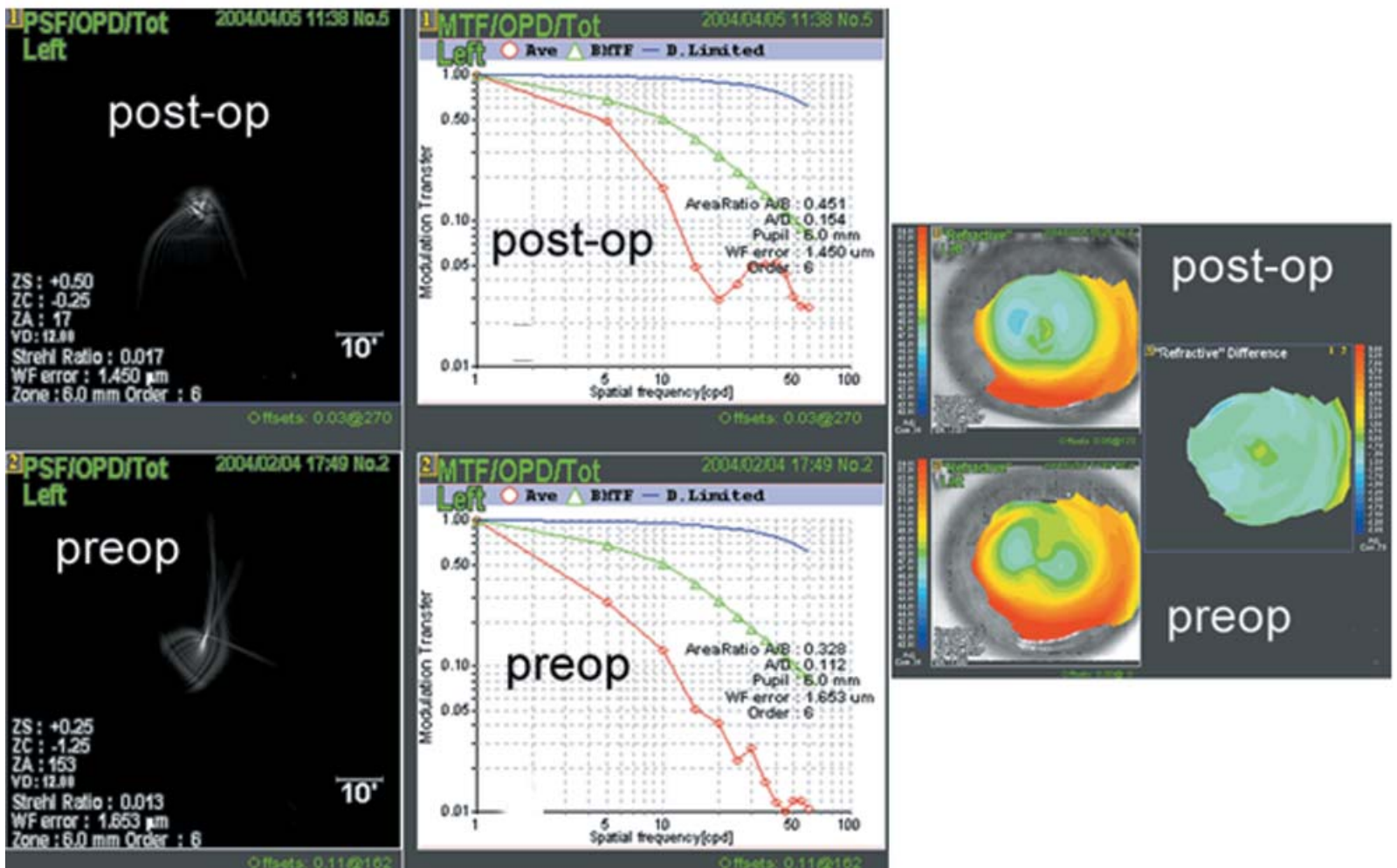

Figure 1. Two cases of decentered ablation retreatment with topography-guided LASIK. Case 1. The preoperative (preop) axial topography shows an inferonasal decentration. The postoperative (postop) topography difference maps show superotemporal flattening at 5 months. Case 2. OPD-Station evaluation showing preoperative (preop) and postoperative (postop) point spread function (PSF) due to all aberrations of the eye including refractive error (lower order aberrations) (PSF/OPD/Tot); postoperative modulation transfer function (MTF) (plotted using logarithmic scales on both axes) of all aberrations of the eyes including refractive error (MTF/OPD/Tot); and refractive corneal topography (Refractive) plotting the refractive power of the anterior cornea (using Snell's Law and simulated ray tracing to obtain the corneal optical power) preoperatively, postoperatively, and the difference. All wavefront measurements were performed for a 6-mm pupil diameter to the 6th Zernike order. 


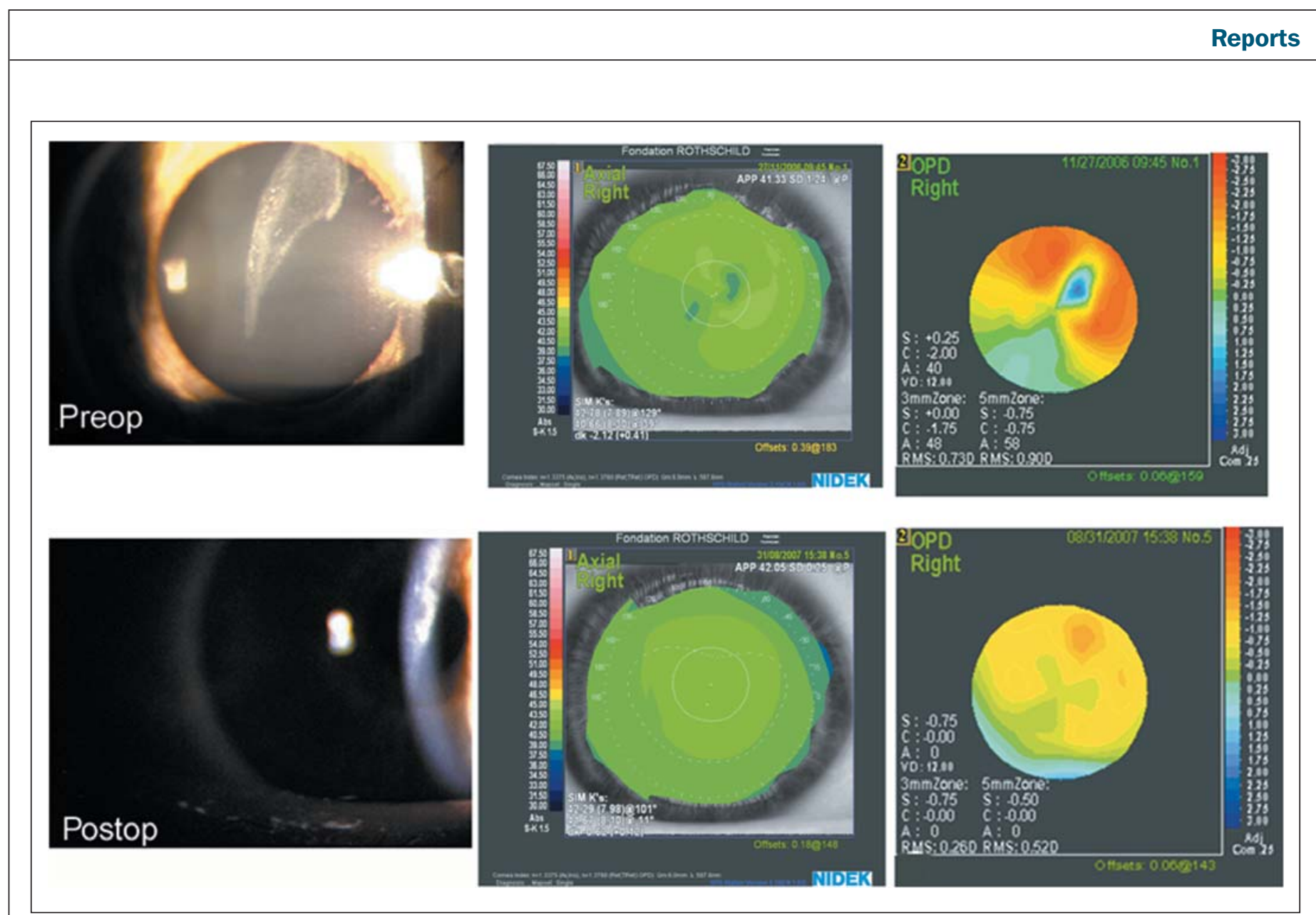

Figure 2. Case 3. Corneal laceration treated with topography-guided photorefractive keratectomy. Preopoperative (preop) shows axial corneal topography; the OPD map is a refractive wavefront map showing a 6.00-diopter (D) difference across the pupil due to laceration. Slit-lamp photography of the eye with previous corneal laceration 9 months after treatment with topography-guided ablation showing resolution of the scar (postop). Postoperative axial corneal topography shows minimal corneal astigmatism $(-0.62 \mathrm{D})$ and symmetric corneal curvature patterns; the OPD map shows $2.50 \mathrm{D}$ in refractive power across the pupil, which is emmetropic centrally (light green) surrounded by mild myopia (light yellow indicating -0.50 to $-0.75 \mathrm{D}$ ).

decreased to $0.650 \mu \mathrm{m}$; coma decreased to $0.512 \mu \mathrm{m}$. Subjectively, the patient reported "partial disappearance" of symptoms and a significant improvement in visual quality. Postoperatively, UDVA was $20 / 20$ and CDVA improved to $20 / 15$ with a MRSE of $-0.50 \times 160^{\circ}$.

Case 2. A 27-year-old man presented for a second opinion with complaints of severe degradation of visual quality at night including persistent starburst, halos, and permanent monocular diplopia 1 month after conventional LASIK. Uncorrected distance visual acuity was 20/20 and CDVA improved to 20/15 with an OPD refraction of $-1.25 \times 160^{\circ}$, with partial reduction of diplopia. Manifest refraction before primary LASIK was $-3.00-1.50 \times 180^{\circ}$. After primary LASIK, there was superonasal decentration with residual toricity (see Fig 1, case 2). The higher order wavefront map was dominated by trefoil $(0.528 \mu \mathrm{m})$ and coma $(0.355 \mu \mathrm{m})$. Higher order aberration RMS was $0.695 \mu \mathrm{m}$. Custom Aspheric Treatment zone algorithm ablation incorporated the treatment of sphere, cylinder, and corneal HOA (irregularity) using aspheric ablation profile \#5.
The flap was relifted for CATz treatment. A 5.5-mm optical zone and 8.5-mm transition zone were used for the sphere correction. Geometric customization of the treatment zones for astigmatism were programmed as follows: $6.0-\mathrm{mm}$ optical zone and $8.9-\mathrm{mm}$ transition zone for the flat meridian of astigmatism; $5.5-\mathrm{mm}$ optical zone and 8.9-mm transition zone for the steep meridian. An optical zone of $5.5 \mathrm{~mm}$ and transition zone of $9.0 \mathrm{~mm}$ were used for the irregularity ablation. Geometric customization produces better outcomes and lower ablation volume compared to standard, noncustomized ablation strategies. ${ }^{7}$ A total of $46.20 \mu \mathrm{m}$ of corneal tissue was removed. Correction of astigmatism was incorporated as it improved visual acuity on manifest refraction. Two months after CATz, there was an improvement in the PSF and the modulation transfer function (MTF), especially at high spatial frequencies (see Fig 1, case 2). The A/B ratio on the MTF graph, which indicates the ratio of the area under the patient's MTF curve compared to a set of emmetropes with excellent visual performance, increased by $12.3 \%$ 
(see Fig 1, case 2). Postoperatively, there was an increase in the functional optical zone and a reduction in corneal astigmatism (see Fig 1, case 2). The patient reported complete resolution of symptoms. Postoperative UDVA was 20/15 and the HOA RMS decreased to $0.392 \mu \mathrm{m}$.

\section{CORNEAL LACERATION}

Case 3. A 28-year-old man presented with corneal laceration due to blunt trauma by a surfboard, complaining of reduced visual acuity and severe scotopic glare (Fig 2 preop). At presentation, UDVA was 20/60, MRSE was $-2.25 \times 40^{\circ}$ with CDVA of $20 / 30$. The laceration caused irregular corneal astigmatism (see Fig 2 preop) and a difference in refractive power of $6.00 \mathrm{D}$ across the pupil (see Fig 2 preop). Corneal HOAs were dominated by coma $(0.63 \mu \mathrm{m})$ and trefoil (RMS $0.75 \mu \mathrm{m})$. Total ocular HOA was $1.23 \mu \mathrm{m}$. Aspheric profile \#4 with a $5.0-\mathrm{mm}$ optical zone and $9.0-\mathrm{mm}$ transition zone was programmed for the sphere and cylinder correction. The irregularity ablation was delivered using an optical zone of $6.5 \mathrm{~mm}$ and a $7.5-\mathrm{mm}$ transition zone. Treatment of refractive error was incorporated due to the increase in visual acuity on MRSE. Nine months after CATz photorefractive keratectomy, there was regular corneal curvature, minimal astigmatism, and a 4.00-D reduction of the refractive gradient across the pupil (see Fig 2 postop). The postoperative manifest refraction was plano and UDVA and CDVA were 20/20. Postoperatively, the patient reported complete resolution of symptoms.

\section{DISCUSSION}

In this case series, we found that patients with reduced visual quality regardless of refractive error could be successfully treated using CATz. In all three cases, there was a decrease in HOAs and the patients were satisfied postoperatively. Successful treatment of highly aberrated corneas has been previously reported with the CATz algorithm. ${ }^{3,4}$ Yoshida et $\mathrm{al}^{3}$ reported the successful treatment of a patient with 15.00 D of refractive change across the pupil due to irregular corneal astigmatism induced by epidemic keratoconjunctivitis. Custom Aspheric Treatment zone algorithm represents an alternative treatment for such cases. Our experience concurs with previous reports. Our treatment strategy was to reduce or eliminate severe changes in corneal curvature and use aspheric algorithms to create large functional optical zones. ${ }^{3,4}$ Postoperative corneal topography maps were more confluent compared to preoperatively (see Figs 1 and 2), and one cornea was prolate postoperatively (see Fig 1, case 2).
One caveat in treating corneas after surgery or trauma is that corneal wound healing and biomechanical responses may cause unpredictable results. This is especially true for corneal scars, as the ablation efficiency may differ on nascent cornea versus scar tissue. In all cases, patients must be counseled for the possibility of an undesirable outcome and additional medical or surgical treatment.

In case 1, we successfully treated HOAs without inducing significant refractive error; in the other cases, we incorporated refractive error into the treatment without inducing significant residual refractive error. This has not been reported with other topographyguided treatment strategies. ${ }^{8}$ Multi-step treatments that incorporate the refractive changes induced by treating the original corneal irregularity may result in greater tissue ablation than required or the length of the treatment may induce an overcorrection due to corneal dehydration. ${ }^{8}$

The use of ocular wavefront-guided treatment may have some limitations as some aberrometers cannot accurately measure eyes with central islands or with severe changes in refractive power across the pupil. ${ }^{5,9,10}$ Additionally, the incorporation of lenticular aberrations that are clinically insignificant in the optical degradation of an eye that has undergone corneal surgery or trauma results in needless tissue removal.

The cases presented show that topography-guided treatment may be used to treat patients with severe iatrogenic or traumatic corneal aberrations that degrade visual quality.

\section{AUTHOR CONTRIBUTIONS}

Study concept and design (D.G.); data collection (D.G.); analysis and interpretation of data (D.G., H.B.); drafting of the manuscript (D.G., H.B.); critical revision of the manuscript (D.G., H.B.)

\section{REFERENCES}

1. Sharma M, Wachler BS, Chan CC. Higher order aberrations and relative risk of symptoms after LASIK. J Refract Surg. 2007;23:252-256

2. Schallhorn SC, Farjo AA, Huang D, Boxer Wachler BS, Trattler WB, Tanzer DJ, Majmudar PA, Sugar A; American Academy of Ophthalmology. Wavefront-guided LASIK for the correction of primary myopia and astigmatism a report by the American Academy of Ophthalmology. Ophthalmology. 2008;115:12491261.

3. Yoshida Y, Nakamura T, Hara S, Yoshida N, Kojima T, Ichikawa K. Topography-guided custom ablation for irregular corneal astigmatism using the NIDEK NAVEX Laser System. J Refract Surg. 2008;24:24-32.

4. Toda I, Yamamoto T, Ito M, Hori-Komai Y, Tsubota K. Topography-guided ablation for treatment of patients with irregular astigmatism. J Refract Surg. 2007;23:118-125.

5. Klein, SA. Problems with wavefront aberrations applied to refractive surgery: developing standards. Ophthalmic Technologies 
XI Proceedings The International Society for Optical Engineering. 2001;4245:47-56.

6. Krueger RR. Corneal topography vs ocular wavefront sensing in the retreatment of highly aberrated post surgical eyes. J Refract Surg. 2006;22:328-330.

7. Gatinel D, Hoang-Xuan T. Geometric customization of optical and transition zone parameters for treatment of compound myopic astigmatism with the NIDEK EC-5000 excimer laser. J Refract Surg. 2007;23:924-930.

8. Lin DT, Holland SR, Rocha KM, Krueger RR. Method for optimizing topography-guided ablation of highly aberrated eyes with the ALLEGRETTO WAVE Excimer Laser. J Refract Surg. 2008;24:S439-S445.

9. Rozema JJ, Van Dyck DE, Tassignon MJ. Clinical comparison of 6 aberrometers. Part 2: statistical comparison in a test group. J Cataract Refract Surg. 2006;32:33-44.

10. Waring G, Dougherty PJ, Chayet A, Fischer J, Fant B, Stevens G, Bains HS. Topographically guided LASIK for myopia using the Nidek CXII customized aspheric treatment zone (CATz). Trans Am Ophthalmol Soc. 2007;105:240-246.

\section{Corneal Spherical Aberration of Eyes With Cataract in a Japanese Population}

Masataka Shimozono, MD; Akiyoshi Uemura, MD, PhD; Yasuhiko Hirami, MD, PhD; Kazuhiro Ishida, MD, PhD; Yasuo Kurimoto, MD, PhD

\section{ABSTRACT}

PURPOSE: To investigate the distribution of corneal spherical aberration in Japanese eyes with cataract for implantation of aspheric intraocular lenses (IOLs).

METHODS: Corneal spherical aberration (Zernike coefficient $Z_{4}^{0}$ ) in the central 6-mm zone was measured with a wavefront analyzer (KR9000PW, Topcon) in 257 eyes of 168 Japanese patients with cataract. Axial length was also measured for each eye.

RESULTS: Mean corneal spherical aberration was $0.203 \pm 0.100$ $\mu \mathrm{m}$ (range: -0.103 to $0.497 \mu \mathrm{m}$ ). A significant negative correlation was found between axial length and corneal spherical aberration $(r=-0.135, P=.036)$.

CONCLUSIONS: Corneal spherical aberration varied among cata-

From the Department of Ophthalmology, Kobe City Medical Center General Hospital (Shimozono, Uemura, Hirami, Ishida, Kurimoto); and the Department of Ophthalmology, Institute of Biomedical Research and Innovation Hospital (Uemura, Hirami, Kurimoto), Kobe, Japan.

The authors have no financial or proprietary interest in the materials presented herein.

Correspondence: Masataka Shimozono, MD, Dept of Ophthalmology, Kobe City Medical Center General Hospital, 4-6, MinatojimaNakamachi, Chuo-ku, Kobe 650-0046, Japan. Tel: 8178302 4321; Fax: 8178302 7537; E-mail: shimozono-tky@umin.ac.jp

Received: July 27, 2009; Accepted: January 13, 2010

Posted online: February 15, 2010 ract patients and correlated with axial length. Japanese patients showed a relatively smaller corneal spherical aberration than previous studies of Caucasians. Preoperative measurement of wavefront aberrations is thus important in using aspheric IOLs. [J Refract Surg. 2010;26(6):457-459.] doi:10.3928/1081597X-20100212-03

W ith advances in cataract surgery, aspheric intraocular lenses (IOLs) have been developed in an attempt to achieve better postoperative optical quality. ${ }^{1}$ Compared to conventional spherical IOLs, these lenses compensate for the positive spherical aberration of the corneal surface, which results in better contrast sensitivity after cataract surgery. ${ }^{2-6}$

Holladay et $\mathrm{al}^{1}$ reported that the positive spherical aberration of the cornea is $0.27 \mu \mathrm{m}$ (for the central 6-mm zone) in Caucasian patients with cataract, and the aspheric IOLs that are presently available are designed based on this spherical aberration value. However, it is possible that corneal spherical aberration varies between ethnic groups. If this is the case, it is necessary to understand the characteristics of corneal aberrations in each ethnic group to select the appropriate aspheric IOL. Furthermore, as some authors have discussed previously, corneal spherical aberration variability may be associated with ocular axial length. ${ }^{7,8}$ Accordingly, we conducted the current study to investigate the distribution of corneal spherical aberration of eyes with cataract in a Japanese population and to analyze the relationship between corneal spherical aberration and axial length.

\section{PATIENTS AND METHODS}

This study was conducted according to the tenets of the Declaration of Helsinki. All patients were scheduled for cataract surgery at Kobe City Medical Center General Hospital.

Wavefront aberration data were obtained with a Hartmann-Shack wavefront analyzer (KR9000PW; Topcon Corp, Tokyo, Japan) for each patient. The Hartmann-Shack images were revised to pupil-center images, and spherical aberrations from the anterior cornea (Zernike coefficient $Z_{4}^{0}$ ) were calculated for the central 6 -mm zone. Axial length was also obtained using the IOLMaster (Carl Zeiss Meditec, Jena, Germany). Those eyes in which data for the central 6-mm zone were not obtained were excluded from the study. Patients with a history of corneal pathology or previous ocular surgery were also excluded. Thus, a total of 257 eyes of 168 patients (81 eyes of 59 men, 176 eyes of 109 women) were enrolled in the study. All patients were Japanese, and mean age was 74.3 \pm 8.7 years (range: 42 to 94 years).

The distribution of corneal spherical aberration and its correlation to axial length was analyzed. 


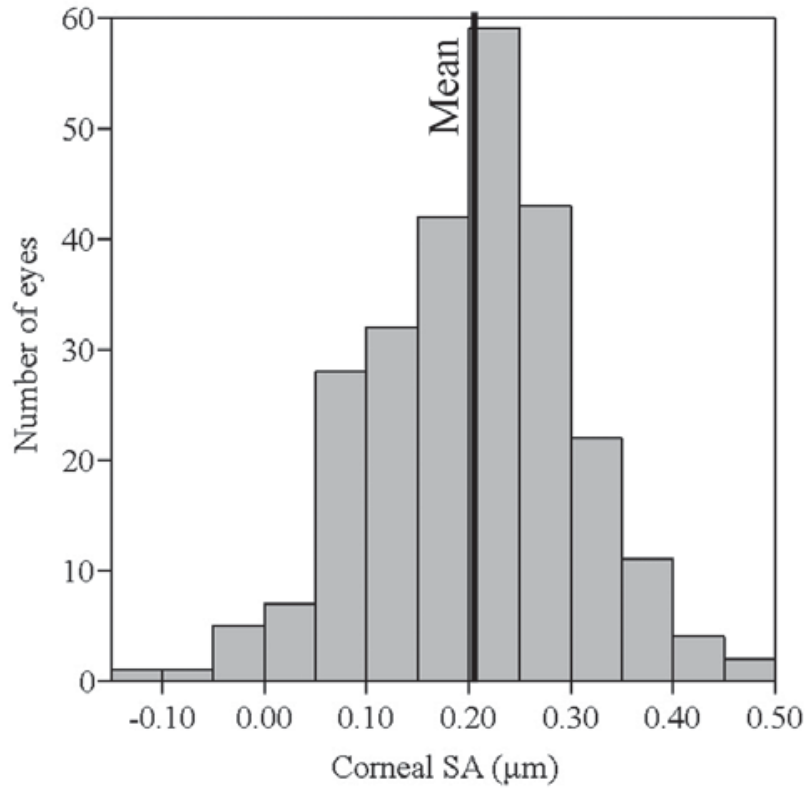

Figure 1. Distribution of corneal spherical aberration $(S A)\left(Z_{4}^{0}\right)$. The mean $Z_{4}^{0}$ value of $0.203 \mu \mathrm{m}$ is represented by the thick solid line.

\section{RESULTS}

Mean spherical aberration $\left(\mathrm{Z}_{4}^{0}\right)$ of the cornea was $0.203 \pm 0.100 \mu \mathrm{m}$ for the central 6-mm zone (95\% confidence interval [CI]: 0.191-0.216 $\mu \mathrm{m}$ ).

Figure 1 is a histogram of the distribution of corneal spherical aberration in the population studied. It reveals an almost symmetrical distribution around the mean spherical aberration value of $0.203 \mu \mathrm{m}$ (range: -0.103 to $0.497 \mu \mathrm{m}) ; 68.5 \%$ of these values were between 0.1 and $0.3 \mu \mathrm{m}, 16.3 \%$ were $<0.1 \mu \mathrm{m}$, and $15.2 \%$ were $>0.3 \mu \mathrm{m}$.

A significant negative correlation was found between axial length and corneal spherical aberration $(\mathrm{r}=-0.135, P=.036)$ (Fig 2).

\section{DIscussion}

Our results demonstrate the mean spherical aberration of the cornea is $0.203 \mu \mathrm{m}$ for the central $6-\mathrm{mm}$ zone. Holladay et $\mathrm{al}^{1}$ reported a mean corneal spherical aberration value of $0.27 \mu \mathrm{m}$, which generally agrees with the literature for Caucasian populations. ${ }^{9,10}$ These data, on the whole, imply a variability in optical aberrations between ethnic groups, as Japanese eyes seem to have smaller corneal spherical aberration than Caucasian eyes.

A concern is that optical aberrations vary from patient to patient. In our study, the corneal spherical aberration ranged from -0.103 to $0.497 \mu \mathrm{m}$. Wang et $\mathrm{al}^{9}$ also found individual variability in corneal spherical aberration, which ranged from 0.069 to $0.511 \mu \mathrm{m}$.

The existence of interracial and individual aberration variability may affect the use of an aspheric IOL. Currently available aspheric IOLs can be classified into two groups according to their target values of postoperative ocular spherical aberration: the Tecnis ZA9003 (Abbott Medical Optics, Santa Ana, Calif) is designed to totally cancel the mean Caucasian corneal spherical aberration of $0.27 \mu \mathrm{m}$, whereas the SN60WF IOL (Alcon Laboratories Inc, Ft Worth, Tex), with its negative spherical aberration of $-0.20 \mu \mathrm{m}$, provides the pseudophakic eye with a residual ocular spherical aberration typically seen in a young eye. Implan-

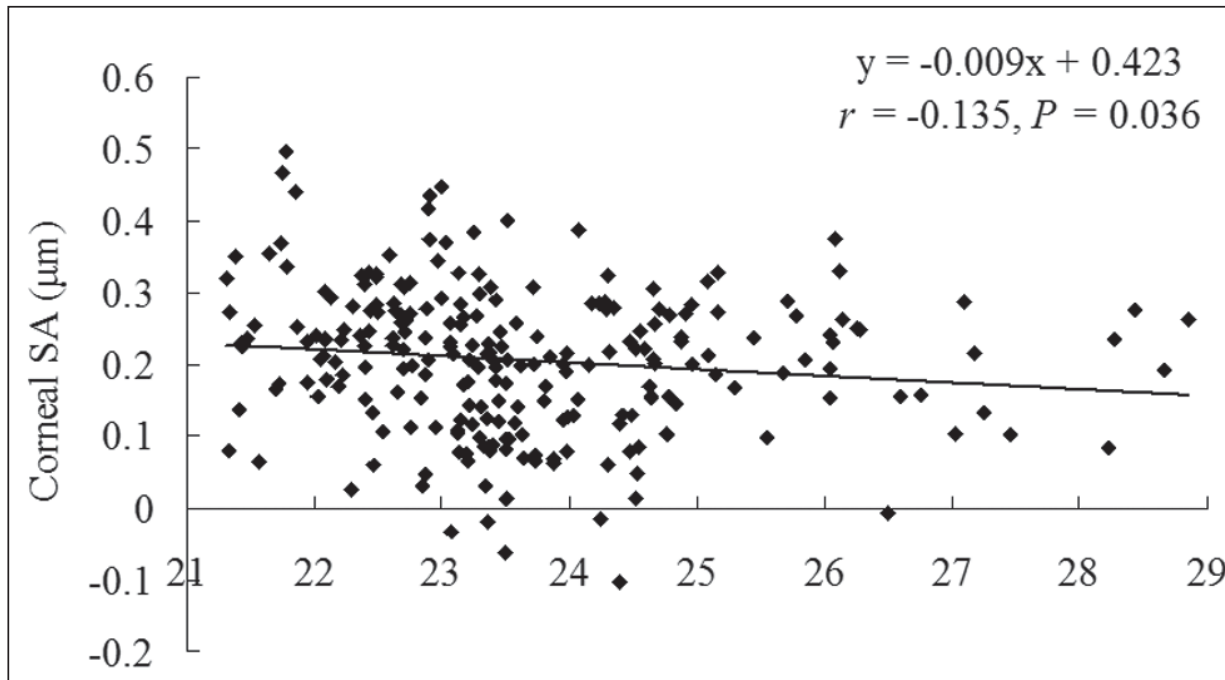

Figure 2. Correlation between axial length and corneal spherical aberration (SA). A significant correlation was found $(r=-0.135$, $P=$.036).

Axial length (mm) 
tation of this IOL would increase the magnitude of ocular spherical aberration by creating larger negative spherical aberration in those eyes with a smaller corneal spherical aberration, especially a spherical aberration of $<0.1 \mu \mathrm{m}$ ( $16.3 \%$ of the eyes in our study), which might be overcorrected even by a relatively smaller compensation effect of the SN60WF. Japanese eyes, which have a smaller corneal spherical aberration than Caucasians by approximately $0.07 \mu \mathrm{m}$, might theoretically be more apt to be overcorrected by the existing aspheric IOLs. Further studies are needed to determine whether the existing IOLs provide optimal visual performance for Japanese eyes.

We also found a negative correlation between axial length and corneal spherical aberration, which is compatible with previous reports. ${ }^{7,8}$ The distribution of axial length may somewhat account for the interracial and individual variability in corneal spherical aberration.

We found that Japanese eyes with cataract had a smaller corneal spherical aberration than previously described Caucasian eyes. Furthermore, corneal spherical aberration varied from patient to patient and was correlated with axial length. Interracial and individual aberration variability thus emphasizes the importance of accurate preoperative measurement of optical wavefront aberrations when using any of the aspheric IOLs now available.

\section{AUTHOR CONTRIBUTIONS}

Study concept and design (M.S., A.U., Y.H., Y.K.); data collection (M.S., A.U., K.I., Y.K.); analysis and interpretation of data (M.S., A.U.); drafting of the manuscript (M.S.); critical revision of the manuscript (A.U., Y.H., K.I., Y.K.); supervision (A.U., Y.K.)

\section{REFERENCES}

1. Holladay JT, Piers PA, Koranyi G, van der Mooren M, Norrby NE. A new intraocular lens design to reduce spherical aberration of pseudophakic eyes. J Refract Surg. 2002;18:683-691.

2. Bellucci R, Morselli S, Piers P. Comparison of wavefront aberrations and optical quality of eyes implanted with five different intraocular lenses. J Refract Surg. 2004;20:297-306.

3. Tzelikis PF, Akaishi L, Trindade FC, Boteon JE. Ocular aberrations and contrast sensitivity after cataract surgery with AcrySof IQ intraocular lens implantation Clinical comparative study. J Cataract Refract Surg. 2007;33:1918-1924.

4. Bellucci R, Morselli S, Pucci V. Spherical aberration and coma with an aspherical and a spherical intraocular lens in normal age-matched eyes. J Cataract Refract Surg. 2007;33:203-209.

5. Mester U, Dillinger P, Anterist N. Impact of a modified optic design on visual function: clinical comparative study. J Cataract Refract Surg. 2003;29:652-660.

6. Awwad ST, Warmerdam D, Bowman RW, Dwarakanathan S, Cavanagh HD, McCulley JP. Contrast sensitivity and higher order aberrations in eyes implanted with AcrySof IQ SN60WF and AcrySof SN60AT intraocular lenses. J Refract Surg. 2008;24:619-625.

7. Cerviño A, Hosking SL, Ferrer-Blasco T, Montes-Mico R, Gonzalez-Meijome JM. A pilot study on the differences in wavefront aberrations between two ethnic groups of young generally myopic subjects. Ophthalmic Physiol Opt. 2008;28:532-537.

8. Kwan WC, Yip SP, Yap MK. Monochromatic aberrations of the human eye and myopia. Clin Exp Optom. 2009;92:304-312.

9. Wang L, Dai E, Koch DD, Nathoo A. Optical aberrations of the human anterior cornea. J Cataract Refract Surg. 2003;29:15141521

10. Beiko GH, Haigis W, Steinmueller A. Distribution of corneal spherical aberration in a comprehensive ophthalmology practice and whether keratometry can predict aberration values. J Cataract Refract Surg. 2007;33:848-858. 